\title{
Delayed Diagnosis of Isolated Postpartum TSH deficiency: Sheehan's syndrome or lymphocytic hypophysitis?
}

\author{
Iuliana Pascu', Minodora Betivoiu', Alexandra Nila', Sorina Martin ${ }^{12}$, Simona Fica ${ }^{12}$ \\ 1. Elias Hospital, Department of Endocrinology, Bucharest, Romania \\ 2. Carol Davila University of Medicine and Pharmacy, Department of Endocrinology, Bucharest, Romania
}

\section{INTRODUCTION}

Sheehan's syndrome (SS) is a rare complication of postpartum hemorrhage resulting in varying degrees of pituitary insufficiency. The diagnosis of SS has often been overlooked and thus delayed for many years due to its nonspecific signs and symptoms. Lymphocytic hypophysitis (LL) is also an uncommon autoimmune disorder that has to be suspected in women with recent delivery presenting with changes of one or more pituitary hormone secretions, especially when associated with other autoimmune endocrine or non-endocrine disorders.

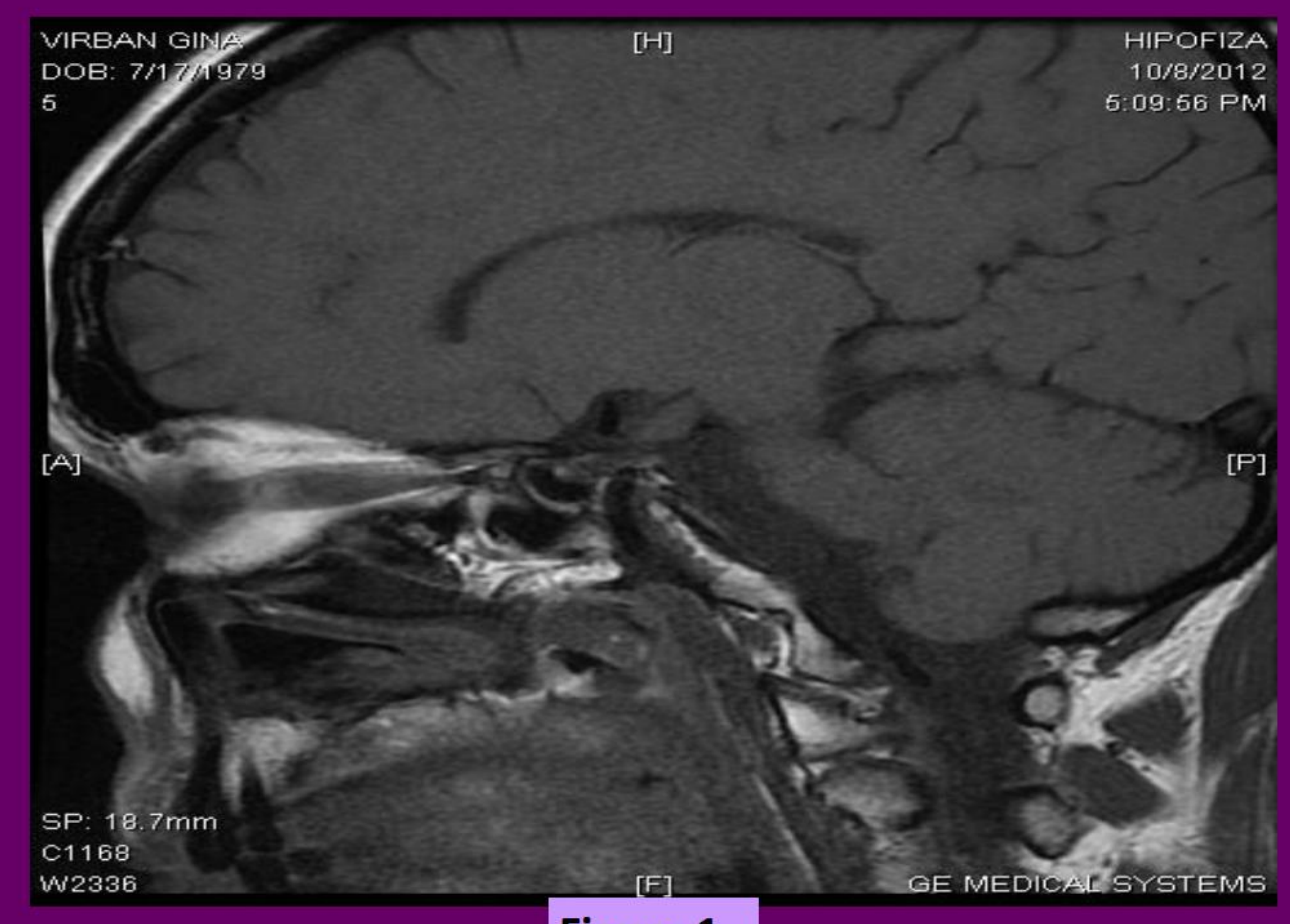

Figure 1

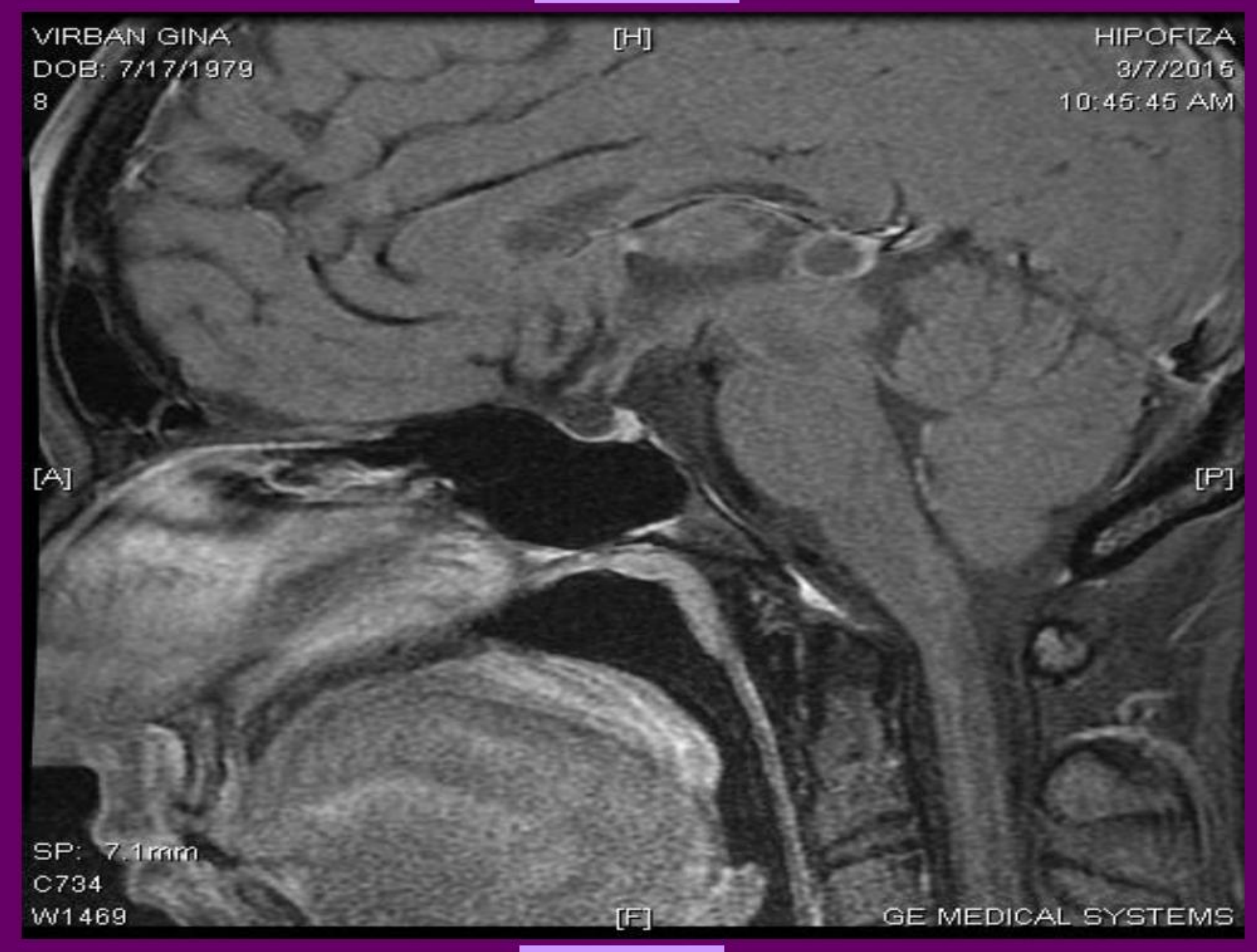

Figure 2

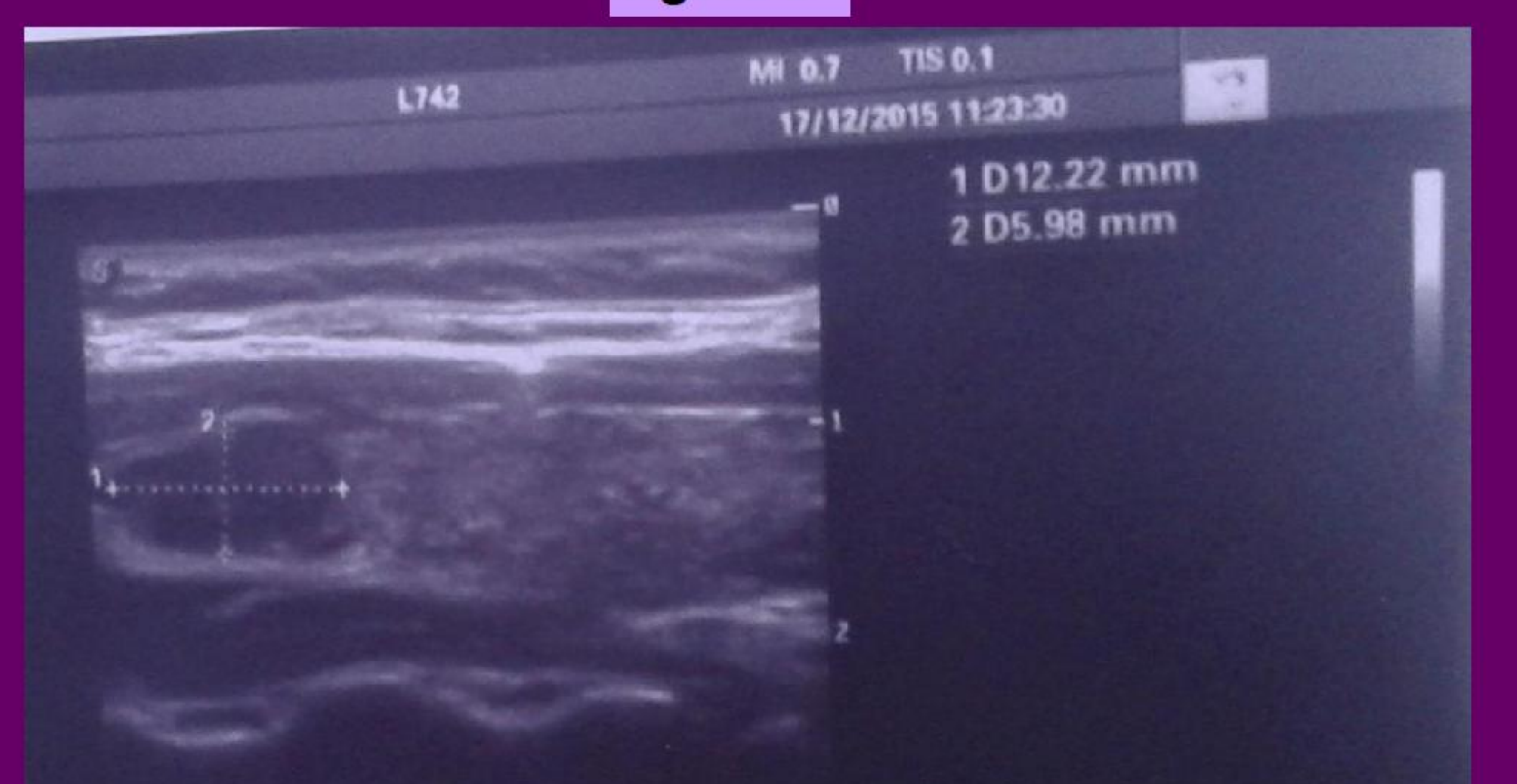

\section{CASE REPORT}

We report the case of a 33-year-old female who presented to our clinic in August 2012 with complaints of fatigue, depression, impaired memory, bradipsychia, upper and lower limbs paresthesias.

In October 2010 the patient had severe postpartum hemorrhage with headache, lactation failure and oligomenorrhea.

Physical examination at admission: $B M I=26 \mathrm{~kg} / \mathrm{m} 2$, dry skin, cold extremities, bradycardia (50/min), low blood pressure $=90 / 60 \mathrm{mmHg}$.

Laboratory results: TSH=1.28 $\mu \mathrm{IU} / \mathrm{ml}, \mathrm{TT} 3<40.0 \mathrm{ng} / \mathrm{dl}, \mathrm{FT} 4<0.30$ $\mathrm{ng} / \mathrm{dl}$, TPOAb $=67.6 \mathrm{IU} / \mathrm{ml}(\mathrm{N}<35 \mathrm{IU} / \mathrm{ml}), 8$ am plasma cortisol=10.1 $\mathrm{mg} / \mathrm{dl}$ with normal increment after Synachtene retard stimulation test, ACTH=12.7 pg/ml, FSH=4.53 $\mathrm{mlU} / \mathrm{ml}, \mathrm{LH}=1.94 \mathrm{mlU} / \mathrm{ml}$, estradiol=38.26 $\mathrm{pg} / \mathrm{ml}$, Prolactin=6.45 ng/ml, IGF1=167.3 ng/ml $(80-277 \mathrm{ng} / \mathrm{ml})$.

Thyroid ultrasound revealed diffuse glandular enlargement with heterogeneous and hypoechoic parenchymal echo pattern that together with the TPOAb levels supported the diagnosis of Hashimoto's thyroiditis (HT) and the right thyroid lobe shows a hypoechoic nodule of 12.22/5.98 $\mathrm{mm}$, without peripheral halo, especially perinodular blood flow, without laterocervical pathological lymph nodes. Pituitary MRI showed empty- sella. The pituitary stalk was slightly thickened and deviated. No pituitary tumors were detected.

The patient was diagnosed with TSH insufficiency and HT and replacement treatment with levothyroxine was started. The follow up was favorable, without functionally progress to combined pituitary dysfunction. In 2014 the patient uneventfully gave birth to a second child.

\section{CONCLUSIONS}

We present the case of a young women diagnosed at 2 years postpartum with isolated TSH deficiency and chronic autoimmune thyroiditis. Long term follow up is mandatory because although the severe postpartum hemorrhage and the empty sella suggest $S S$ the association with HT may rise the suspicion of a LL.

The three pictures from top to bottom:

Figure 1: pituitary MRI in October 2012

Figure 2: pituitary MRI in March 2015

Figure 3: thyroid ultrasound showing hypoechoic nodule of $12.22 / 5.98 \mathrm{~mm}$ in the right thyroid lobe 